\title{
The Effectiveness of Automated Sonic Bloom Method in An IoT-Based Hydroponic System
}

\author{
Seli Suhesti ${ }^{1 *}$, Aji Gautama Putrada ${ }^{2}$, Rizka Reza Pahlevi ${ }^{3}$ \\ ${ }^{1,2,3}$ School of Computing, Telkom University \\ Bandung, Indonesia \\ *selisuhesti@student.telkomuniversity.ac.id
}

\begin{abstract}
One of the solutions for food security is to plant using the hydroponic method. Hydroponics can increase productivity and help hydroponic grow faster, and facilitate monitoring hydroponic growth. Users can use two useful technologies: sonic bloom and the Internet of Things (IoT). However, in previous studies, the two systems have not been interconnected. This study proposes to evaluate the effectiveness of combining the two systems mentioned, hence creating an automated sonic bloom method in an IoT-based hydroponic system. As proof of concept, this system is implemented with bok choi as the hydroponic plant using the DFT technique, the automated sonic bloom is embedded to the IoT system with DF Player Mini module, RTC module, and speakers, and the evaluation is done by comparing growth parameters and the crop parameters. The results show that the system with sonic bloom produces a fresh weight of $0,44-0,56 \mathrm{~g}$ and a dry weight of $0,21-0,33 \mathrm{~g}$. The mentioned results are superior to the system without sonic bloom, where fresh weight is $0,17-0,25 \mathrm{~g}$, and dry weight is $0,08-0,13 \mathrm{~g}$. The conclusion is that the IoT-based sonic bloom system effectively increases the growth and hydroponic production rates.
\end{abstract}

Keywords: Sonic Bloom, IoT, Hydroponic

\section{INTRODUCTION}

A griculture is one sector that the people of Indonesia need to provide sufficient food availability [1]. Farming is challenging in urban communities because there is no agricultural land to grow crops. The decline in the farmland area occurs due to many buildings, industries, infrastructure, settlements, and other nonagricultural regions [1][2]. Lack of land to grow crops can be one of the problems in food security. One of the solutions is to grow plants using hydroponic methods [3][4]. Hydroponics is a plant produced by utilizing water or a solution of nutritious minerals without soil media. Hydroponics can avoid many soil media problems such as cutworms and soil-borne diseases that damage crops.

The usage of sonic bloom technology can increase the productivity of hydroponics. Sonic bloom uses high-frequency sound waves combined simultaneously with nutrition [5]. These sound waves will stimulate the opening of stomata and affect the absorption of carbon dioxide movement around the leaves [7]. One application of sonic bloom technology is to use music. Sonic bloom technology by utilizing music is a novelty by focusing on sound characteristics that are acceptable to plants. 
Previous research has also implemented hydroponics with the Internet of Things (IoT). IoT is a technology that connects to sensors and other intelligent devices that function as a facilitator for communication and information exchange [10]. IoT can control hydroponic plants' growth, such as temperature control, humidity, water level, and water flow control. However, sonic bloom technology and IoT hydroponic are not interconnected yet. With IoT, sonic bloom sound activation can be made automatically [11]. This solution can ease users in controlling and monitoring the schedule of the sonic bloom sounds.

The purpose of this research is to implement a hydroponic system by applying a proposed Internet of Things (IoT)-based sonic bloom and evaluate its effectiveness on hydroponic growth. Evaluation is done by comparing several parameters at the time of growth and when the plants have been harvested. The parameters measured at the time of change were plant height, leaf height, and leaf width. After the plants were harvested, fresh weight and dry weight were measured.

The research methodology is as follows: The IoT system created consists of a NodeMCU connected to a sensor. Furthermore, the NodeMCU collects data from sensors and then publishes it to a message queue telemetry transport (MQTT) Broker, and then the data will be stored in a database. In addition, users can monitor through the dashboard of the Node-Red platform that subscribes to the MQTT [12]. In the Node-Red dashboard, data from sensors will be visible, and music playback timings for sonic bloom can be made. The implementation of sonic bloom on the IoT system utilizes an MP3 player module and a speaker.

Tests are carried out using two systems, namely a system that applied sonic bloom and a system that did not apply sonic bloom. The measurement of plant height, leaf height, leaf width, fresh weight, and dry weight will be compared to determine whether sonic bloom can increase plant productivity. In hydroponic plants' growth, some things must be considered: paying attention to fresh and dry weight. Fresh weight is the total weight of plants without roots recorded after the plants are harvested. Fresh weight testing is carried out to determine how much water and nutrient absorption from hydroponic plants [8]. While dry weight is the weight recorded after the plant is dried at a temperature higher than the ambient air temperature $\left(80^{\circ} \mathrm{C}\right)[9]$. The planting medium used in this study is the Deep Flow Technique (DFT) [7].

\section{LITERATURE REVIEW}

Previous research has widely discussed Hydroponic plant monitoring systems using IoT. IoT systems can make it easier for farmers to manage hydroponic crops. The purpose of this study was to monitor factors such as correct $\mathrm{pH}$ levels, air temperature, relative humidity, water nutrient levels, and water irrigation and to ensure higher farmer efficiency success rates [11]. The components required in the manufacture of this system are Raspberry pi, water Pump (Venus Aqua 033F Aquarium Top Filter), which is used to control the flow of water into the system. The results obtained from this study are the influence of fans and sprinklers of relative humidity and air temperature.

Research [13] discusses IoT technology for hydroponic growth that aims to design and implement hydroponic systems that use IoT to monitor various parameters such as water level $\mathrm{pH}$, nutrients in the water, and moisture. The purpose of this research is the same as research which distinguishes is that this system uses NodeMCU as a microcontroller. The sensors used in this study were DHT11 sensors, $\mathrm{pH}$ sensors, and electrical conductivity circuits [11]. Data from the designed system is collected on ThingSpeak and displayed on the "IoT MQTT Panel" mobile app, which will help users to monitor and control factory conditions easily.

Research [18] discusses the Deep Flow Technique (DFT) hydroponic system by connecting IoT. The study used the fuzzy Sugeno method to combine the IoT system to create a water circulation system in hydroponic plants. The research created two different systems: circulation system with IoT and circulation system without IoT. The creation of the two systems aims to compare which plants will produce better crops. The study results showed that circulation systems with IoT get better results than systems that do not use IoT. 
Research [20] implemented IoT communication using publish and subscribe methods on a cloud-based approach. This research proposes the design of architectural models implemented in system topology. This topology aims to monitor and control the feeding of nutrients in hydroponics. Users can access the topology as Cloud SaaS (Software as a service) [20]. Merging cloud computing with IoT systems can help manage each device's messages and collect and organize data or information through middleware and applications.

Research [7] sonic bloom technology has been used to help the growth of hydroponic plants with the utilization of music. The purpose of using sonic bloom is to increase the productivity of lettuce plants. The music used in this study is jazz music, Javanese gamelan music, and heavy metal music. Plants are treated with a different type of music every one hour every day for 23 days. Sonic bloom makes the stimuli of stomata open and affects the movement of carbon dioxide around plants to affect the absorption of carbon dioxide around the leaves [7].

The contribution of this research is a sonic bloom hydroponic system combined with an IoT solution. The contribution can be seen in table I. Table I shows the comparison between previous research and this research. Furthermore, the proposed system adds original sound to the sonic bloom. There are speakers for the output of sonic bloom sound for systems with sonic bloom.

TABLE I

RESEARCH COMPARISON IN HYDROPONIC SYSTEMS

\begin{tabular}{ccccc}
\hline \hline Reference & IoT Solution & Sonic Bloom & Sound & Compared With \\
\hline$[5]$ & No & Yes & Sounds of nature & No Sound \\
\hline$[7]$ & No & Yes & $\begin{array}{c}\text { Javanese gamelan } \\
\text { music }\end{array}$ & No Sound \\
\hline$[11]$ & Yes & No & None Comparison \\
\hline Proposed System & Yes & Yes & $\begin{array}{c}\text { Javanese gamelan } \\
\text { music with the } \\
\text { original sound of } \\
\text { sonic bloom }\end{array}$ & No Sound \\
\hline \hline
\end{tabular}

\section{RESEARCH METHOD}

\section{A. Hydroponic System Design}

The hydroponic system design proposed in this research uses the Deep Flow Technique (DFT). DFT is a hydroponic method that uses water as a medium to supply nutrients to plants through reservoirs [14]. The working principle of the DFT hydroponic system is to circulate plants. Flow technique in a hydroponic system cultivates hydroponic plants by placing plant roots on the water layer. The DFT technique has a flat installation to retain the nutrient water in the pipe. The advantage of the DFT technique is that DFT saves electricity because users do not always have to turn on the water pump, and the plant will be faster to harvest.

Fig. 1 shows the design of a hydroponic system using DFT techniques. There is a reservoir that will be a water reservoir for hydroponics. The reservoir is helpful as a place for water circulation, and there is a small aquarium pump as a source of water expenditure connected to the pipes. Hydroponic plants are planted using pipes measuring $107 \times 30 \times 40 \mathrm{~cm}$. The pipe will drain water from the reservoir then the water will flow to the plant and be returned to the reservoir. The pipe consists of two levels, and each group has the same number of holes. There are speakers for the output of sonic bloom sound produced from the designed IoT 
system. Speakers are placed next to the hydroponic plant so that the plant's sound from the sonic bloom can be heard clearly.

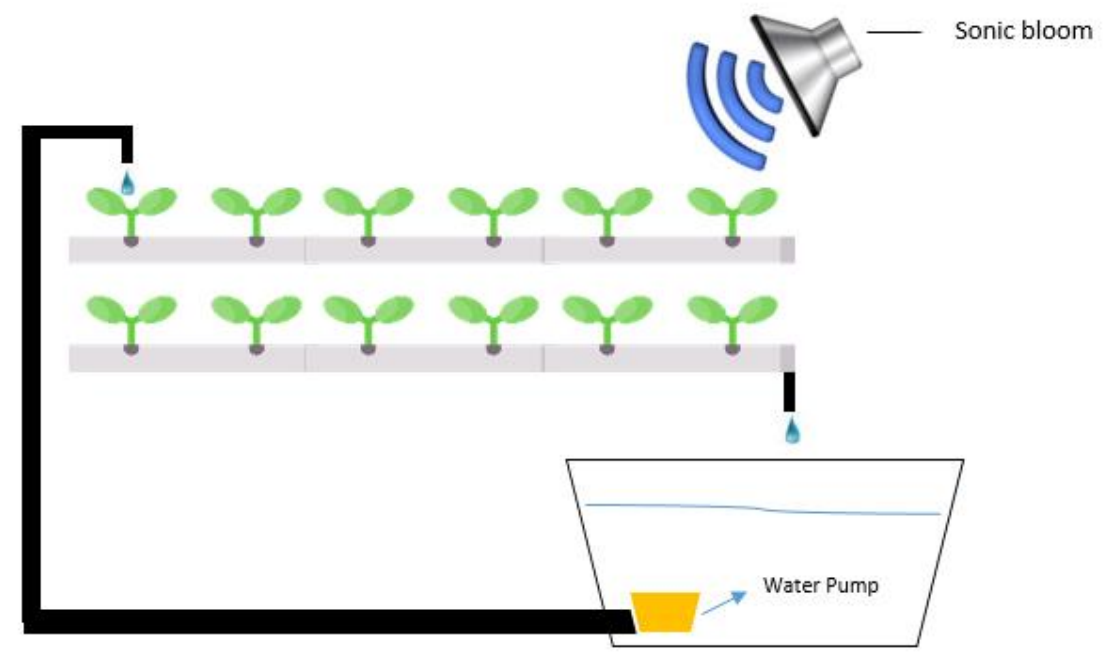

Fig. 1. Hydroponic system design and sonic bloom illustration

\section{B. Methodology}

In the block diagram in Fig. 2, there are four sensors, namely DHT11 for temperature and humidity, ultrasonic sensor to detect the water level in the pipe, RTC sensor to set music playback time, and DF Player Mini to store music to be played for sonic bloom. DF Player Mini is connected with some speakers to output the resulting sound. There are relays and water pumps to regulate the water circulation in hydroponic plants. The relay will activate when the pump turns on or off. The state depends on the temperature and humidity conditions resulting from the DHT11 sensor. The water pump will be off when the humidity is $\geq 70$, and the temperature is $\leq 18$.

The four sensors and relays are connected to and send data through the NodeMCU by publishing it with MQTT to the server [15]. MQTT is a connectivity protocol used for Internet of Things (IoT) applications [15]. The data published in MQTT will be displayed on the Node-Red dashboard, where the dashboard monitors the data sent by the sensor. Data received by Node-Red will be stored in a MongoDB database.

Fig. 3 consists of the flow chart of the system. Sensors comprised of DHT11, ultrasonic, RTC, DF Player Mini, and relay will send data to NodeMCU. NodeMCU will read the data from these sensors, and then the data will be published to MQTT. Data that has been published to MQTT will be sent to Node-Red to create an interface of the system. Data sent to Node-Red will appear on the Node-Red dashboard so that users can view information from the sensors' data and control the time to play the sonic bloom music. Data already sent to Node-Red will be saved into the MongoDB database.

\section{The Implementation of Sonic Bloom}

Table II shows that the sound-treated for hydroponic plants has two different types of sounds, namely Javanese gamelan music and the original sound of sonic bloom like birdsong. Each sound is played for two hours each day for 21 days of planting at different times of the day. Javanese gamelan sound is played at 07.10 a.m. In contrast, the original sound of sonic bloom is played at 2.10 p.m. Sonic Bloom treatment is carried out after the administration of nutrients to hydroponic plants. Scenario 1 is used for a sonic bloom system, and Scenario 2 is used without a sonic bloom. 


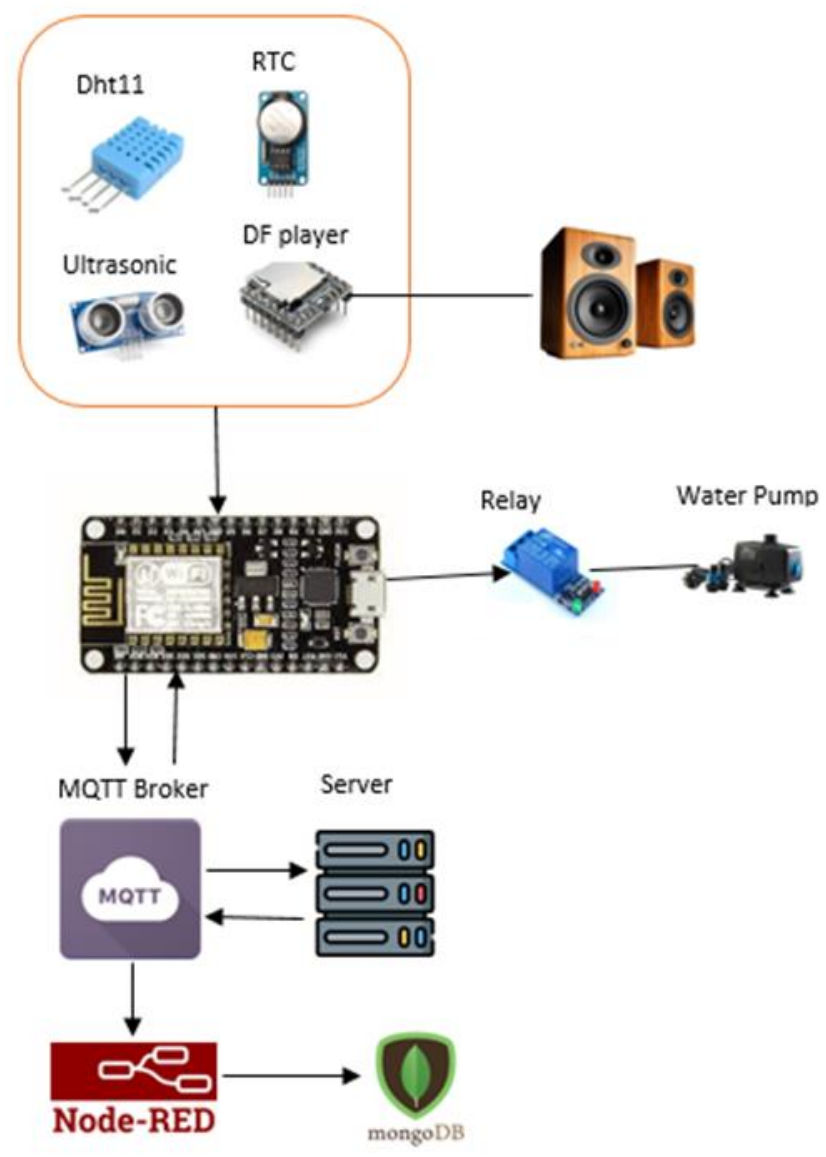

Fig. 2. Block diagram of IoT-based hydroponic system with sonic bloom

\section{Fresh Weight and Dry Weight Testing Scenarios}

This test was conducted between the sonic and sonic bloom systems. The purpose of the comparison is to know which plants produce better plant growth. The plan that implements sonic bloom is treated with two different sounds: Javanese gamelan music sounds and original sonic bloom sounds such as birdsong sounds. Hydroponic plants used are bok choi plants 14 days old after the seedling period.

TABLE II

SCENARIOS OF SONIC BLOOM AND WITHOUT SONIC BLOOM SYSTEMS

\begin{tabular}{ccc}
\hline \hline & Sound Type & Schedule \\
\hline Scenario 1 & Javanese gamelan music & $\begin{array}{c}\text { Sounded at } 7.10 \text { a.m. for an hour every } \\
\text { day }\end{array}$ \\
\cline { 2 - 3 } & The original sound of sonic bloom & $\begin{array}{c}\text { Sounded at } 2.10 \begin{array}{c}\text { p.m. for an hour every } \\
\text { day }\end{array} \\
\text { Scenario 2 }\end{array}$ \\
\cline { 2 - 3 }
\end{tabular}




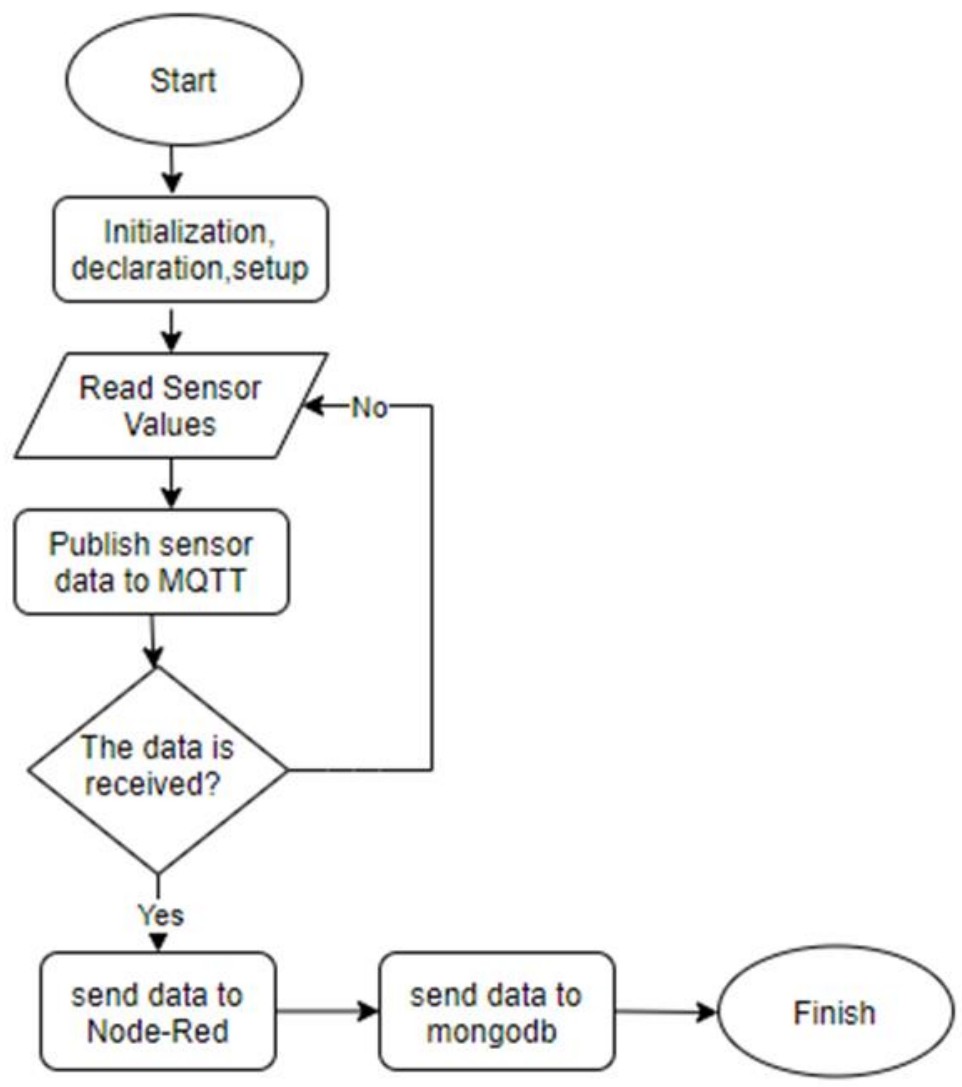

Fig. 3. Flowchart of IoT-based hydroponic system

The systems with sonic bloom consist of a DHT11 sensor, ultrasonic, RTC, DF Player Mini, and relay. Furthermore, the system without sonic bloom uses a DHT11 sensor, ultrasonic, and relay only. The outputs of both systems are stored on the Node-Red dashboard. Both methods have the same workflow, which distinguishes only the sensors used.

\section{Fresh Weight Testing}

Plant weight is an indicator to see the development of a plant, increased biomass, and plant size because sound exposure can trigger stomata openings to be wider to increase the fresh weight of plants and crop productivity. Fresh weight measurement is done by separating the root with the head of the plant by cutting the base of the root [17]. Testing was conducted when the plant had been through growth for 21 days with different sound type treatments using digital scales [6].

\section{Dry Weight Testing}

Dry weight measurement is an advanced measurement of fresh weight measurement. The separated and cleaned plant roots and titles are then baked in the oven at a temperature of about $80^{\circ}$ [16]. Once dry, the plant is measured using a digital scale. This measurement is done when the plant has been through growth for 21 days.

\section{RESULTS AND DISCUSSION}

\section{A. Implementation}

In implementing the DFT hydroponic system, hydroponic circuits are made in pipes measuring $107 \mathrm{x}$ $30 \times 40 \mathrm{~cm}$ as a place to put bok choi [18]. The pipe is equipped with a water container for water circulation 
and an aquarium water pump to deliver nutrient water into the pipe to plant the bok choi. There are two pipe designs for the DFT hydroponic system with sonic bloom and the DFT hydroponic system without sonic bloom.

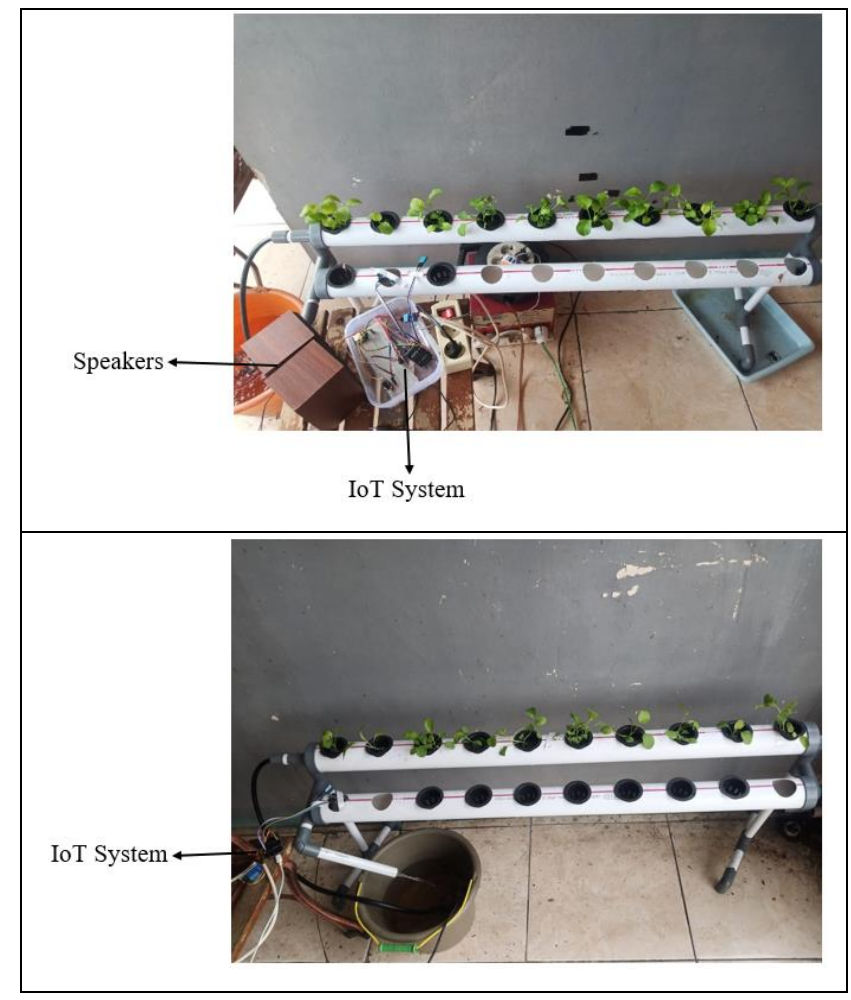

Fig. 4. Implementation of DFT hydroponic system with sonic bloom (above) and without sonic bloom (below)

Fig. 4 shows the implementation of the DFT hydroponic system with sonic bloom and without sonic bloom. In the scenario with sonic bloom, speakers are placed with bok choi plants as sound output from sonic bloom. The hardware consists of a DHT11 sensor, ultrasonic, RTC, DF Player Mini, and relays connected to the power outlet. Moreover, the outlet is used to connect the water pump. Then the system has only a DHT11 sensor, ultrasonic, and relays without sonic bloom to power the water pump. There are two types of hardware systems: hardware systems with sonic bloom and hardware without sonic bloom. The hardware consists of a DHT11 sensor, ultrasonic, and relay connected to a power outlet. The outlet is used to connect the water pump.

There are four pages on the Node-Red dashboard as the interface of the DFT hydroponic system. The user interface can be seen in Fig 5. At the top part of the figure is the first page that displays temperature and humidity data. There are two displays, one for the system with sonic bloom and one without sonic bloom. At the bottom left part of the figure is the second page, which displays information about the water level in the pipe. Again, there are two displays with sonic bloom and one without sonic bloom.

At the figure's middle right part is the third page, which contains information on the status of the water pump, whether the pump is on or off. Also, there are two displays, one for the system with sonic bloom and one for the system without sonic bloom. At the bottom right part of the figure is the last page, which sets the time for music playback on sonic bloom. Data from system sensors with sonic bloom and systems without sonic bloom are shown on the Node-Red dashboard. Set Music 1 is for Javanese gamelan sound, and set music two is for the original sonic bloom sound. This setting is specific for the system with sonic bloom, whereas the system without sonic bloom does not utilize music and sound. 


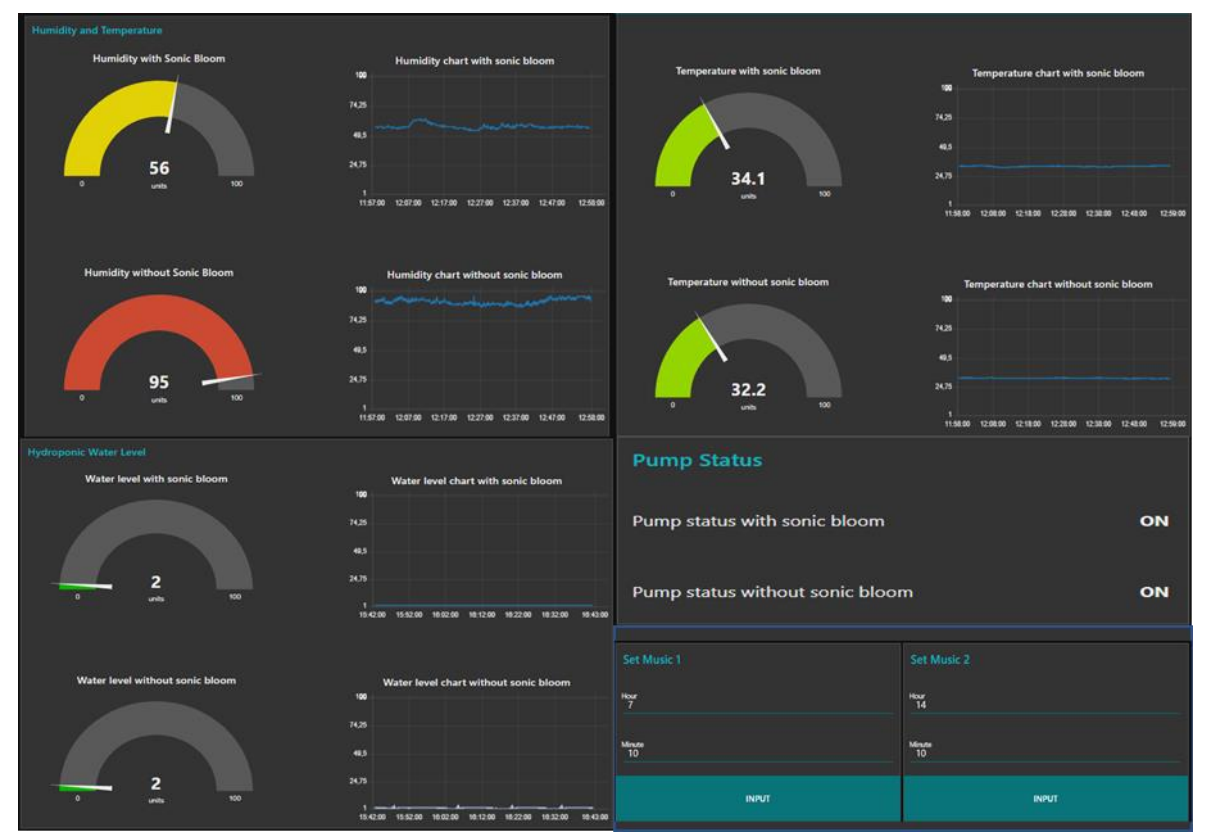

Fig. 5. Interface for user application side of the IoT-based hydroponics

\section{B. Sonic Bloom Effectivity Test Results}

Bok choi hydroponics are planted for 21 days after the seedling period. In conjunction with feeding nutrients in the bok choi hydroponics, Sonic bloom treatment is carried out. Nutrition in bok choi hydroponics consists of water and nutrition $\mathrm{AB}$ mix. The mixture measure is 1:1, which flows into the pipe and then into the pump [19].

Bok choi hydroponic growth is measured by plant height, leaf height, and leaf width that grow every day. The average comparison of bok choi hydroponic growth with sonic bloom and without sonic bloom can be seen in the charts in Fig. 6 to Fig. 8.

The line chart in Fig. 6 explains the comparison of the average plant height of the bok choi hydroponic growth in the system with sonic bloom and the system without sonic bloom. The seventh day with sonic bloom produces a plant height of $15-16,5 \mathrm{~cm}$ with an average of $12,78-14,21 \mathrm{~cm}$. Day 14 with sonic bloom has a $20-21 \mathrm{~cm}$ plant height with an average of $17,85-18,91 \mathrm{~cm}$. Day 21 with sonic bloom makes a $23-26 \mathrm{~cm}$ plant height with an average of $22,15-23,88 \mathrm{~cm}$.

On the other hand, Plant height for the system without sonic bloom on day 7 produces a height of 12 $-14 \mathrm{~cm}$ with an average of $9,78-12,04 \mathrm{~cm}$. Day 14 makes a plant height of $15.8-17 \mathrm{~cm}$ with an average of $14,78-15,9 \mathrm{~cm}$. Day 21 has a plant height of $17,5-19,2 \mathrm{~cm}$ with an average of $16,8-18,15 \mathrm{~cm}$.

The line chart in Fig. 7 compares the average leaf height of the bok choi hydroponic growth with sonic bloom and the system without sonic bloom. On the seventh day with sonic bloom produces a leaf height of 6,2 $-7,3 \mathrm{~cm}$ with an average of $4,83-5,58 \mathrm{~cm}$. Day 14 with sonic bloom has a leaf height of 7,5-8,4 cm with an average of $6,68-7,82 \mathrm{~cm}$. Day 21 with sonic bloom makes leaf height of 10,2-11 cm with an average of 9,22 $-9,85 \mathrm{~cm}$.

On the other hand, leaf height for the system without sonic bloom on day 7 produces a leaf height of $4,5-5,3 \mathrm{~cm}$ with an average of 3,68-4,38 cm. Day 14 has a leaf height of 5,5-6,8 cm with an average of $5,14-6,4 \mathrm{~cm}$. Day 21 makes leaf height $8-8,4 \mathrm{~cm}$ with an average of 7,11-7,61 cm. 


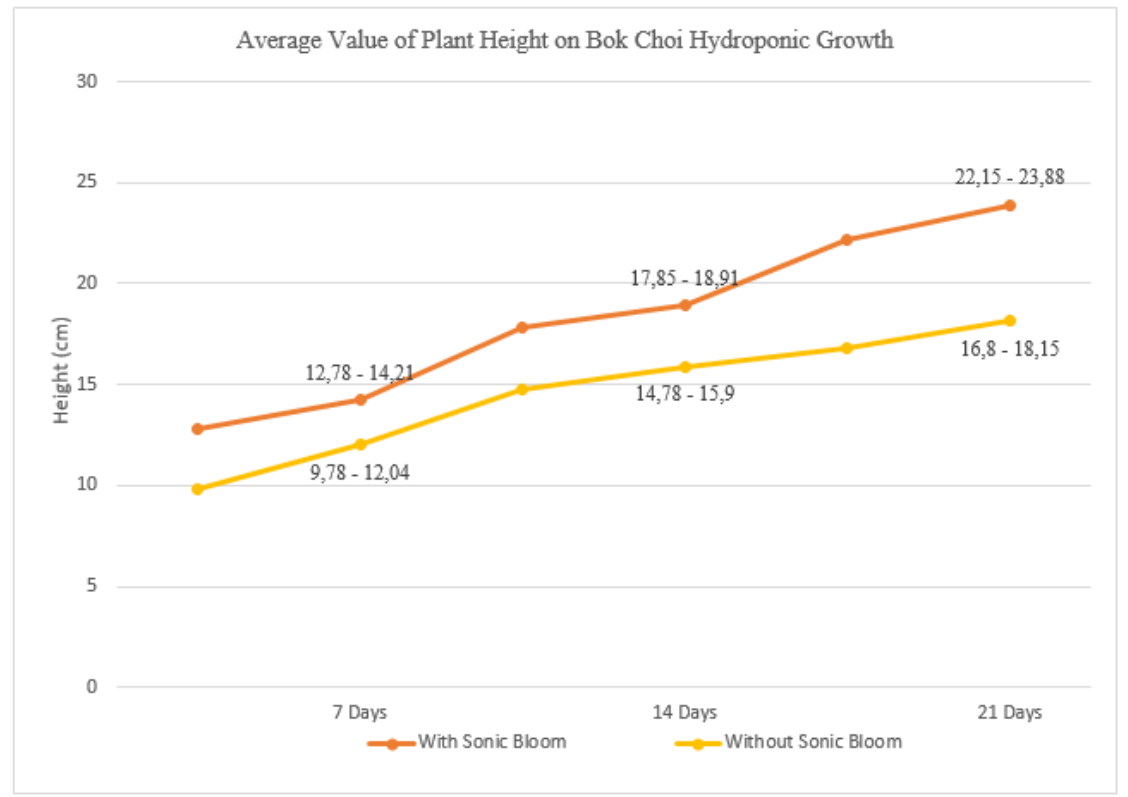

Fig. 6. Line chart comparison of average plant height on bok choi hydroponic growth

The line chart in Fig. 8 compares the average leaf width of the bok choi hydroponic growth with sonic bloom and the system without sonic bloom. On the seventh day with sonic bloom produces a leaf width of 4,5 $5,2 \mathrm{~cm}$ with an average of $3,46-4,15 \mathrm{~cm}$. Day 14 with sonic bloom has a leaf width of $6,5-7,2 \mathrm{~cm}$ with an average of 5,52-6,4 cm. Day 21 with sonic bloom makes leaf width of $8,5-9 \mathrm{~cm}$ with an average of 7,68 $8,15 \mathrm{~cm}$.

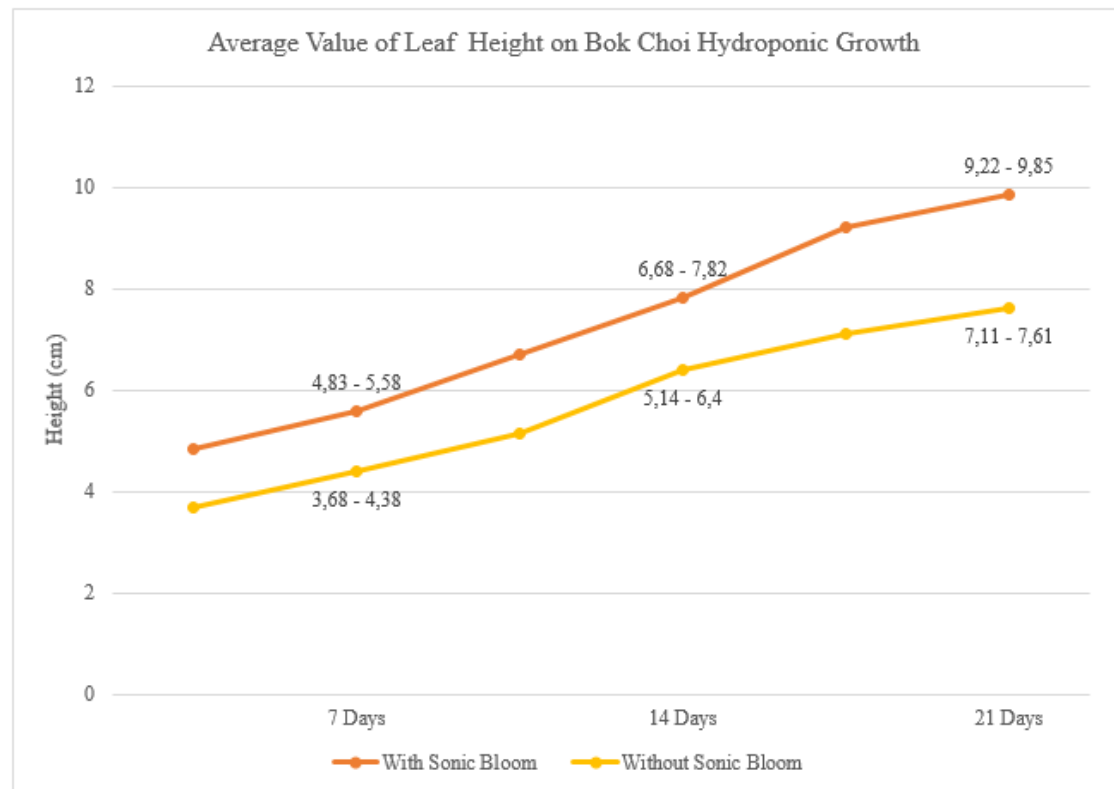

Fig. 7. Line chart comparison of average leaf height on bok choi hydroponic growth

On the other hand, leaf width for the system without sonic bloom on day 7 produces a leaf width of $3,5-4 \mathrm{~cm}$ with an average of 2,68 -3,28 cm. Day 14 makes a leaf width of 4,5-5,2 cm with an average of $3,92-4,68 \mathrm{~cm}$. Day 21 has a leaf width of $6,4-7 \mathrm{~cm}$ with an average of $5,52-5,92 \mathrm{~cm}$. 
One of the parameters that must be calculated in hydroponic plant growth is the measurement of fresh weight and dry weight. Fresh weight and dry weight measurements are done after bok choi is 21 days old or after harvest. Fresh weight measurement is done by separating the roots and headers on the plant and then measuring using digital scales. After doing fresh weight measurement, the next step is measuring dry weight by putting hydroponic plants in the oven for \pm 5 minutes until the plant is dry and then weighed using digital scales. The system with sonic bloom produces a fresh and dry weight that is heavier than the system without sonic bloom.

The box plot chart in Fig. 9 explains the comparison of the fresh weight and dry weight of the bok choi hydroponic growth in the system with sonic bloom and the system without sonic bloom. The design with sonic bloom produces a fresh weight of $0,44-0,56 \mathrm{~g}$ and a dry weight of $0,21-0,33 \mathrm{~g}$. The system without sonic bloom has a fresh weight of $0.17-0.25 \mathrm{~g}$ and a dry weight of $0.08-0.13 \mathrm{~g}$.

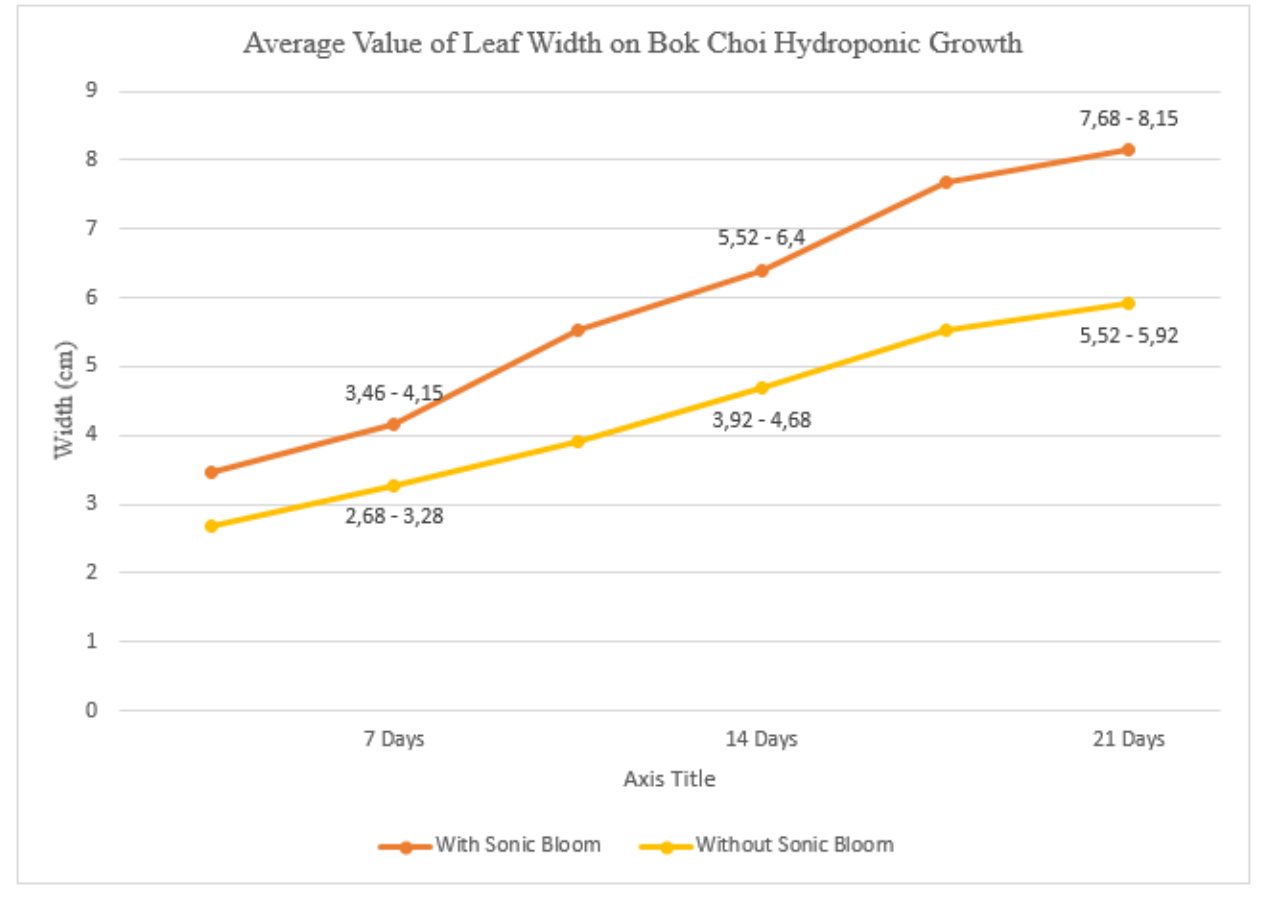

Fig. 8. Line chart comparison of average leaf width on bok choi hydroponic growth

Based on the metrics' graphics, after testing bok choi hydroponic with two different systems, there are differences in the growth results of bok choi hydroponics. Bok choi hydroponic planted with sonic bloom system has faster growth than the system without a sonic bloom in plant height, leaf height, and leaf width. Fresh weight and dry weight measurements also differ in weight between systems that use sonic bloom and methods without sonic bloom. It appears that the system using sonic bloom has a more significant weight than the system that does not use sonic bloom. This result proves that the sonic bloom system is more effective than the system without sonic bloom.

The results of bok choi hydroponic planting are summarized in Table III. The table compares the impact between the hydroponic system with sonic bloom and without sonic bloom. The design with sonic bloom is superior in every indicator. 


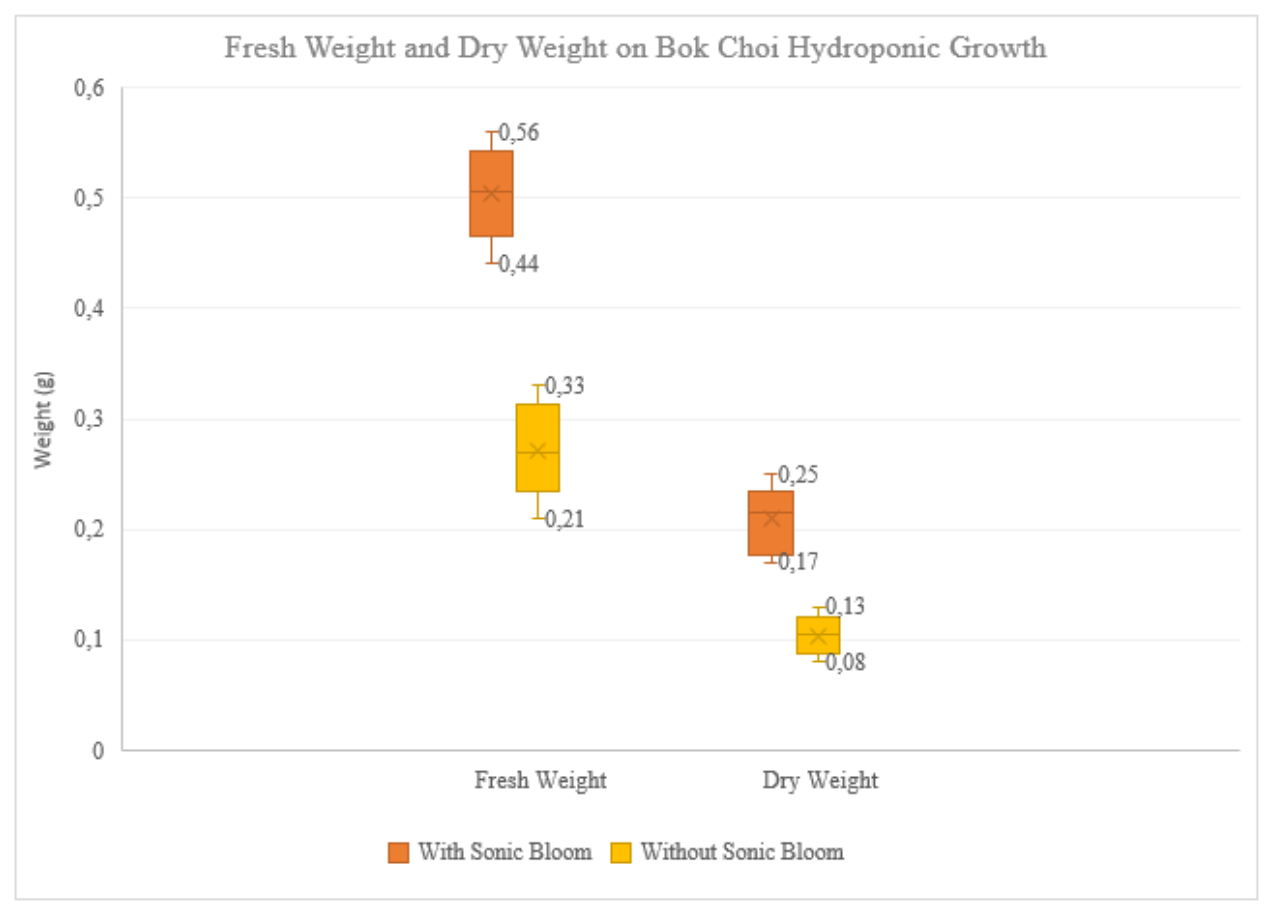

Fig. 9. Box plot comparison of fresh weight and dry weight on bok choi hydroponic growth

\section{Discussion}

Analysis of test results is discussed after conducting trials on hydroponics bok choi using two different systems, namely the system with sonic bloom and the system without sonic bloom. Sonic bloom is combined with an IoT system to monitor bok choi hydroponic plant growth and set the playback time of sonic bloom sound using an RTC sensor. The implementation of sonic bloom with IoT system uses DF Player Mini as a sound source connected to the speakers as the output of the sound. In the process of research, DHT11 and ultrasonic are placed on top of hydroponic pipes and relays connected with a power outlet to regulate the ignition process of the water pump. The system governs components and interactions such as the IoT system in research [11], whereas the contribution of this research is that it implements sonic bloom automation. Study [11] does not register the success rate of the proposed IoT system, whereas this research successfully proves the effectiveness of the IoT-based hydroponic system.

The implementation of sonic bloom in this research demonstrates better growth than the system without sonic bloom. The results shown in this research follow the sonic bloom result in the related study [7], which also uses sounds with Javanese gamelan music and obtained good growth results. Farmers usually use the original sound of sonic bloom to help grow crops. Also, in research [5][7], it was shown that sonic bloom could help plants grow faster. The contribution of this research is that the sonic bloom in this research is embedded in an IoT-based system, thus enabling automation. This solution can ease users in controlling and monitoring the schedule of the sonic bloom sounds.

\section{CONCLUSION}

An IoT-based hydroponic system that implements the sonic bloom method has been successfully implemented. After 21 days of planting periods, the bok choi hydroponic grown with sonic bloom system has a final average plant height of $22,15-23,88 \mathrm{~cm}$, an absolute middle leaves height of $9,22-9,85 \mathrm{~cm}$, and final average leaf width of 7,68 $-8,15 \mathrm{~cm}$, a resulting fresh weight of $0,44-0,56 \mathrm{~g}$, and a resulting dry weight of $0,21-0,33 \mathrm{~g}$. This result is superior to the system without sonic bloom, where it produces a final average plant height of 16,8-18,15 cm, an absolute middle leaves height of 7,11-7,61 cm, and the last average leaves width 
of 5,52-5,92 cm, a resulting fresh weight of $0,17-0,25 \mathrm{~g}$ and a resulting dry weight of $0,08-0,13 \mathrm{~g}$. The results show that the plants in the IoT system that use sonic bloom effectively increase the growth rate and the production rate of hydroponic plants.

TABLE III

RESULT TABLE OF BOK CHOI HYDROPONIC

\begin{tabular}{ccc}
\hline \hline \multirow{2}{*}{ Indicator } & \multicolumn{2}{c}{ Result } \\
\cline { 2 - 3 } & With Sonic Bloom & Without Sonic Bloom \\
\hline Plant Height & $\mathbf{2 2 , 1 5}-\mathbf{2 3 , 8 8 ~ C m}$ & $16,8-18,15 \mathrm{~cm}$ \\
\hline Leaf Height & $\mathbf{9 , 2 2}-\mathbf{9 , 8 5} \mathbf{C m}$ & $7,11-7,61 \mathrm{~cm}$ \\
\hline Leaf Width & $\mathbf{7 , 6 8}-\mathbf{8 , 1 5} \mathbf{C m}$ & $5,52-5,92 \mathrm{~cm}$ \\
\hline Fresh Weight & $\mathbf{0 , 4 4}-\mathbf{0 , 5 6} \mathbf{g}$ & $0,17-0,25 \mathrm{~g}$ \\
\hline Dry weight & $\mathbf{0 , 2 1}-\mathbf{0 , 3 3} \mathbf{g}$ & $0,08-0,13 \mathrm{~g}$ \\
\hline \hline & REFERENCES
\end{tabular}

[1] Herman and N. Surantha, "Intelligent monitoring and controlling system for hydroponics precision agriculture," 2019 7th Int. Conf. Inf. Commun. Technol. ICoICT 2019, pp. 1-6, 2019, DOI: 10.1109/ICoICT.2019.8835377.

[2] A. Mulyani, S. Ritung, and I. Las, "Potensi dan Ketersediaan Sumberdaya Lahan untuk Mendukung Ketahanan Pangan," J. Penelit. dan Pengemb. Pertan., vol. 30, no. 2, pp. 73-80, 2016, doi: 10.21082/jp3.v30n2.2011.p73-80.

[3] M. V Shewale and D. S. Chaudhari, "Internet of Things Based Plant Monitoring System for Hydroponics Agriculture," International Journal of Emerging Technologies and Innovative Research, vol. 5, no. 8, pp. 242-249, 2018.

[4] S. Charumathi, R. M. Kaviya, J. Kumariyarasi, R. Manisha, and P. Dhivya, "Optimization and Control of Hydroponics Agriculture using IoT," Asian J. Appl. Sci. Technol., vol. 1, no. 2, pp. 96-98, 2017, [Online]. Available: https://papers.ssrn.com/sol3/papers.cfm?abstract_id=2941105.

[5] I. Pujiwati, B. Guritno, N. Aini, and S. P. Sakti, "Examining Use of Sonic Bloom Technology on the Stomata Opening of Drought-Stressed Soybean," Biosci. Biotechnol. Res. Asia, vol. 15, no. 4, pp. 861869, 2018, DOI: 10.13005/bbra/2695.

[6] T. B. H. Zulkifli et al., "Analisis Pertumbuhan, Asimilasi Bersih Dan Produksi Terung Dan Pupuk Npk Growth.," Agrotek Trop., vol. 8, no. 2, pp. 295-310, 2020.

[7] J. Prasetyo and I. B. Lazuardi, "Pemaparan Teknologi Sonic Bloom Dengan Pemanfaatan Jenis MusikTerhadap Pertumbuhan Vegetatif Tanaman Selada Krop ( Lactuca Sativa L ),” J. Keteknikan Trop. dan Biosist., vol. 5, no. 2, pp. 189-199, 2017.

[8] P. Huang, L. de-Bashan, T. Crocker, J. W. Kloepper, and Y. Bashan, "Evidence that fresh weight measurement is imprecise for reporting the effect of plant growth-promoting (rhizo)bacteria on growth 
promotion of crop plants," Biol. Fertil. Soils, vol. 53, no. 2, pp. 199-208, 2017, DOI: 10.1007/s00374016-1160-2.

[9] S. Goddek and T. Vermeulen, "Comparison of Lactuca sativa growth performance in conventional and RAS-based hydroponic systems," Aquac. Int., vol. 26, no. 6, pp. 1377-1386, 2018, DOI: 10.1007/s10499-018-0293-8.

[10] A. Komninos, G. Georgiadis, and A. Koskeris, "Internet of things applications on monitoring hydroponics through wireless sensor networks," Information, Intell. Syst. Appl., vol. 1, no. 1, pp. 1-5, 2020, doi: $10.26220 /$ iisa.3330.

[11] C. J. G. Aliac and E. Maravillas, "IOT hydroponics management system," 2018 IEEE 10th Int. Conf. Humanoid, Nanotechnology, Inf. Technol. Commun. Control. Environ. Manag. HNICEM 2018, pp. 15, 2019, doi: 10.1109/HNICEM.2018.8666372.

[12] S. Chanthakit and C. Rattanapoka, "MQTT based air quality monitoring system using node MCU and node-red," Proceeding 2018 7th ICT Int. Student Proj. Conf. ICT-ISPC 2018, pp. 3-7, 2018, DOI: 10.1109/ICT-ISPC.2018.8523891.

[13] R. Vidhya and K. Valarmathi, "Automatic Monitoring of Hydroponics System Using IoT," Lect. Notes Data Eng. Commun. Technol., vol. 35, no. June, pp. 641-648, 2020, DOI: 10.1007/978-3-030-321505_62.

[14] S. Pramono, A. Nuruddin, and M. H. Ibrahim, "Design of a hydroponic monitoring system with deep flow technique (DFT),” AIP Conf. Proc., vol. 2217, no. April 2020, DOI: 10.1063/5.0000733.

[15] M. Poongothai, A. L., and R. Priyadharshini, "Implementation of IoT based Smart Laboratory," Int. J. Comput. Appl., vol. 182, no. 15, pp. 31-34, 2018, DOI: 10.5120/ijca2018917853.

[16] K. D. Jayanti, "Pengaruh Berbagai Media Tanam Terhadap Pertumbuhan Dan Hasil Tanaman Pakcoy (Brassica Rapa Subsp. Chinensis),” J. Bioind., vol. 3, no. 1, pp. 580-588, 2020, doi: 10.31326/jbio.v3i1.828.

[17] T. B. H. Zulkifli et al., "Analisis Pertumbuhan, Asimilasi Bersih Dan Produksi Terung Dan Pupuk Npk Growth.," Agrotek Trop., vol. 8, no. 2, pp. 295-310, 2020.

[18] U. Nurhasan, A. Prasetyo, G. Lazuardi, E. Rohadi, and H. Pradibta, "Implementation IoT in System Monitoring Hydroponic Plant Water Circulation and Control," Int. J. Eng. Technol., vol. 7, no. 4.44, p. 122, 2018, DOI: 10.14419/ijet.v7i4.44.26965.

[19] B. Hermanto, D. Habibie, A. F. Lubis, and R. A. Syahputra, "Analysis of Pakcoy Mustard (Brassica rapa ) Growth using Hydroponic System with AB Mix Nutrition,” J. Phys. Conf. Ser., vol. 1819, no. 1, 2021, DOI: $10.1088 / 1742-6596 / 1819 / 1 / 012059$.

[20] M. A. Triawan, H. Hindersah, D. Yolanda, and F. Hadiatna, "Internet of Things using publish and subscribe method cloud-based application to NFT-based hydroponic system," Proc. 2016 6th Int. Conf. Syst. Eng. Technol. ICSET 2016, pp. 98-104, 2017, DOI: 10.1109/FIT.2016.7857546. 